\title{
DERLEME
}

\section{Siber Zorbalığın Önlenmesinde Önemli Bir Kavram: Dijital Ebeveynlik ve Pediatri Hemşireliği}

\section{Dilek ULUDAŞDEMIRR ${ }^{1}$ Sibel KÜÇÜK ${ }^{1}$}

\section{$\ddot{\mathbf{O Z Z}}$}

Dijital yerlilerin büyüme ve gelişmesini olumsuz etkileyen siber zorbalığın sıklığı gün geçtikçe artmaktadır. Çocuk ve gençlerin siber zorbalıkla başa çıkma stratejilerinin yetersiz kalması siber zorbalığın önlenmesi ve müdahalesinde ebeveynlere önemli bir sorumluluk yüklemekte, geleneksel rollerinin yanında dijital ebeveynlik rollerine de sahip olmaları gerekmektedir. Ebeveynlerin dijital ebeveynlik becerilerini kazanmalarında eğitim, danışmanlık, savunucu rolleri gereğince pediyatri hemşireleri yol gösterici olmaktadır. Bu çalışmada siber zorbalığın önlenmesi ve müdahalesinde dijital ebeveynlik kavramı, ebeveynlerin sahip olması gereken dijital okuryazarlık, dijital etik, dijital dünyanın farkında olmak, dijital dünyada kontrol ve yenilikçilik rolleri ile pediyatri hemşirelerinin dijital ebeveynlik becerilerinin geliştirilmesinde ebeveynlere sağlayacağı katkılar hakkında bilgilere yer verilmiştir.

Anahtar Kelimeler: Çocuk Hemşireliği; Dijital Ebeveynlik; Siber Zorbalık

\section{An Important Concept in Prevention Of Cyberbullying: Digital Parenting And Pediatric Nursing Dilek ULUDAŞDEMIR ${ }^{1}$ Sibel KÜÇÜK ${ }^{1}$}

\begin{abstract}
The frequency of cyberbullying, which negatively affects the growth and development of digital natives, is increasing day by day. Inadequate coping strategies of children and young people with cyberbullying impose an important responsibility on parents in the prevention and intervention of cyberbullying. Parents need to have digital parenting roles as well as traditional parenting roles. Pediatric nurses are guiding parents in terms of their education, counseling and advocacy roles in acquiring digital parenting skills. The aim of this study is to provide information about the concept of digital parenting in the prevention and intervention of cyberbullying, digital literacy, digital ethics, awareness of the risks of the digital world, the roles of control and innovation in the digital world, and the contributions of pediatric nurses to the development of digital parenting skills.
\end{abstract}

Keywords: Cyberbullying; Digital Parenting; Pediatric Nursing

${ }^{1}$ Ankara Yıldırım Beyazıt Üniversitesi Sağlık Bilimleri Fakültesi Hemşirelik Bölümü Çocuk Sağlığı ve Hastalıkları Anabilim Dalı, Ankara, Türkiye. Sorumlu Yazar: Dilek ULUDAŞDEMIR 


\section{GíRiș}

Teknolojinin gelişmesi ile birlikte yeni kavramlar da hayatımıza girmeye başlamıştır. Dijital yerli ve dijital göçmen kavramları bu yeni kavramlar arasında yer almaktadır. Dijital yerliler (1) olarak adlandırılan günümüz çocuk ve ergenleri, dijital cihazlar ve iletişimin vazgeçilmez kaynağ internet ile çevrili bir dünyaya doğmakta, hatta yürümeyi ve konuşmayı bile öğrenmede dijital dünyaya çok hızlı adapte olmaktadır (1-4). Dünyada ve ülkemizde çocuk ve gençlerle yapılan çalışmalar bu durumu doğrulamaktadır. Çocukların bir yaşını tamamlamadan önce cep telefonu, tablet ile tanıştığ1, okul öncesi dönemde kendine ait cep telefonu, tablet ve bilgisayarı olduğu, haftada ortalama dokuz saatini internette geçirdiği ve bir sosyal medya hesabına sahip olduğu bildirilmektedir $(5,6)$. İnternet kullanım ve dijital cihazların kullanım sıklığının ergenlik dönemiyle birlikte arttığı, günde üç saatten fazla zamanlarını dijital dünyada geçirdikleri bilinmektedir $(5,7)$. Uyar ve Hasdemir (8) çocukların \%75.5'inin internet kullanmayı kendi kendine öğrendiklerini, Kaşıkçı ve arkadaşları (9) ise çocukların bu konuda kendilerini ailelerinden daha yeterli gördüklerini bildirmektedir.
Eğlenmek, iletişim kurmak, gazete dergi okumak, blog yazmak, alışveriş yapmak (10) gibi birçok nedenlerle kullanılan internet ve dijital cihazlar, amacı dışında kullanıldığında çocuk ve gençleri çeşitli şekillerde tehdit etmektedir (11). Siber zorbalık, internette çocuklar ve gençler arasında yaşanan olumsuzlukların başında gelmektedir. Fiziksel gelişiminin yanında bilişsel gelişim sürecinde olan çocuk ve gençlerin siber zorbalık nedeniyle savunmasız olduğu, bu nedenle mağduriyet yaşadıkları, siber zorbalıktan kaçınmak ve korunmak için ebeveyn desteğine ihtiyaç olduğu görülmektedir (12).

Büyük çoğunluğu dijital göçmen (1) olarak adlandırılan ebeveynlere internete erişim sıklığ 1 , cep telefonu kullanım oranlarıyla doğrudan ilişkili olan siber zorbalığın önlenmesinde, çocuk ve gençlerin bilgilendirilmesinde çeşitli sorumluluklar düşmektedir. Ancak teknolojik cihazlar ve internet kullanımının yaygınlaşmadığı dönemde dünyaya gelen ve dijital göçmen (1) ebeveynlerin siber zorbalık farkındalıklarının yetersiz olduğu bilinmektedir (12). Siber zorbalığ1 önleme ve müdahale programları geliştirilirken ebeveynlerin de dahil edilmesi gerektiğinin 
belirtilmesine rağmen yapılan çalışmaların yetersiz olduğu ve ya dijital ebeveynlik becerilerinin tek bir başlık altında değil de ayrı ayrı değinildiği görülmektedir (13). Bu nedenle ebeveynlerin dijital okuryazarlık, dijital etik gibi rolleri içinde barındıran dijital ebeveynlik becerileri (14) desteklenerek çocuklarının siber zorbalıktan uzak durması ve mağdur olması engellenebilir. Çocukların sağlıklı büyüme ve gelişmesinde ebeveynlere yol gösteri olan pediyatri hemşirelerinin, siber zorbalığın önlenmesi için ailelere dijital ebeveynlik becerilerinin kazandırılmasında da rehberlik etmesi son derece önem taşımaktadır.

\section{SIBBER ZORBALIK ve Dijital}

\section{EBEVEYNLILIKK}

\section{Siber Zorbalık}

Siber zorbalık“cep telefonu, tablet, kişisel bilgisayar aracılı̆̆ıyla hem çevrimiçi hem çevrimdışı olarak karşı taraftaki kişiye kasıtlı olarak yapılan saldırgan davranışları" içeren bir kavramdır (15-17). Telefon ile saldırgan, tehdit içerikli mesaj göndermek, sosyal medya hesaplarında izinsiz ve küçük düşürücü paylaşımlarda bulunmak, çevrimiçi oyun, sohbet odalarında bir kişiyi dışlamak, yok saymak, dedikodu çıkarmak gibi davranışlar siber zorbalık; bu davranışlara maruz kalma ise siber mağduriyet olarak tanımlanmaktadır (18,19, Şekil 1).

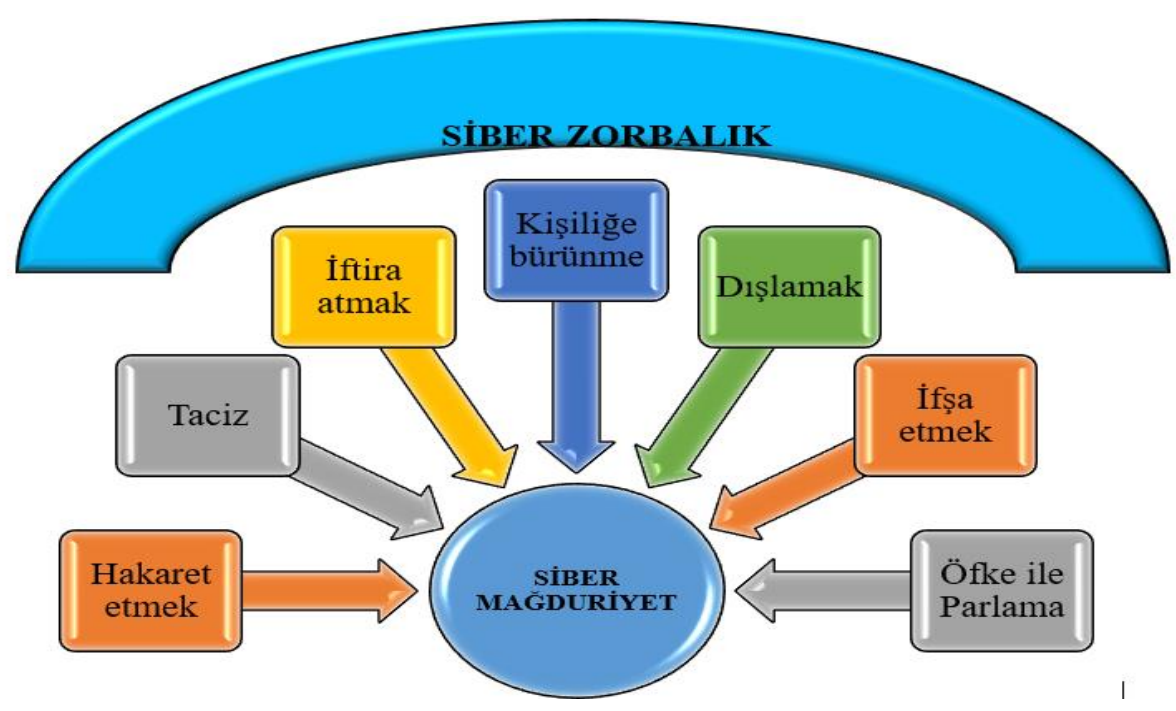

Şekil 1. Siber zorbalık biçimleri*

*Araştırmacılar tarafindan ilgili literatür doğrultusunda oluşturulmuştur (18). 
Dünyada ve ülkemizde çocuk ve gençlerde siber zorbalık oranları yaklaşık \%60'ları bulurken, siber mağduriyet oranları $\% 70$ 'in üzerinde görülmektedir (7,12,20-23). Zhu ve arkadaşlarının (24) Amerika, İspanya, Çin, İsrail, İtalya, Almanya, Güney Kore ile arasında ülkemizde yayınlanan araştırmaların da dahil olduğu toplam 63 ülkeyi kapsayan sistematik incelemesinde siber zorbalık yaygınlığının son beş yılda hızla arttığı, ilkokuldan üniversiteye kadar geniş bir yaş grubunu etkilediği belirlemiştir.

Yakın arkadaşlar, komşular ve ya internet aracılığıyla tanışılmış yabancı kişiler tarafindan gerçekleştirilebilen (25) siber zorbalığın nedenlerine bakıldığında internette ve ya sosyal medyada üç saatin üzerinde zaman geçirme, birden fazla sosyal medya hesabı kullanma, kimliğini gizleyebilme düşüncesi, kişisel ve iletişim bilgilerinin paylaşılması, internette tanışılan kişilerle arkadaş olmak empati yapamama, siber zorbalığ1 şaka olarak algılamak gibi çocuk ve gençlerin kendilerinden kaynaklanan nedenlerin yanında $(7,24,26)$ ebeveynlerle ilgili nedenlerde literatürde yer almaktadır.

Ebeveynlerin eğitim seviyesi, çocukları ile olan iletişimi, internet kullanımına yönelik otoriter tutum sergilemesi, sosyoekonomik gelir seviyesi gibi nedenlerin yanında ebeveynlerin dijital dünyanın yeniliklerine adapte olmada ve getirdiği riskler konusunda bilgi yetersizliği ön plana çıkarak siber zorbalığı ve siber mağduriyeti etkilemektedir (27) (Tablo 1).

Siber zorbalığın en önemli çevresel nedenlerinden biri de ebeveynlerin siber zorbalık farkındalı̆̆ının yetersiz olmasıdır. İnan-Kaya ve arkadaşları (2018) tarafından yapılan çalışmada yaş aralığg $10-18$ arasında olan adölesanlara sahip ebeveynlerin \%91.1'i internetin riskleri arasında kişisel bilgileri paylaşmak, \%88.6'sı internet bağımlılığı olarak bildirmişlerdir. Ancak ebeveynlerin siber zorbalık (\%48.1) ve siber mağduriyet (\%64.6) gibi riskler hakkında daha az bilgili oldukları görülmüştür (34). Uludaşdemir ve Küçük 'ün (7) çalışmasında da benzer şekilde ebeveynlerin neredeyse tamamı çocuklarının siber zorba ve ya siber mağdur olmadığını belirtmesine karşın, çocukların \%56.5'nin siber zorba \%65.5'nin siber mağdur olduğu belirlenmiştir (7). Caivano ve arkadaşlarının (35) çalışmasında ilkokul çağında çocuğu olan ebeveynlerin çocuklarının siber zorbalık davranışının farkında olmadığı belirlenmiştir. Alfakeh ve arkadaşları (36) 
ebeveynlerin \%43 siber zorbalığın geleneksel zorbalıktan daha zararlı olduğunu belirtmiş, yalnızca \%27.9'u ise siber zorbalığı önlemede ebeveynlerin desteğinin ve denetiminin önemli olduğunu söylemiştir. Martín-Criado, Casas \& Ortega-Ruiz (27) çalışmasında ebeveynlerin yalnızca \%37.5'i çevrimiçi riskleri önleme stratejilerini hakkında bilgi sahibi olduğu, \%84.1'inin siber zorbalıkla ilgili bilgi gereksinimi olduğu belirlenmiştir. Görüldüğü gibi çocuk ve gençleri tehdit eden siber zorbalık hakkında ebeveynlerin farkındalığı ve bilgileri yetersizdir. Ebeveynlerin çocuklarının siber zorbalık ve ya siber mağduriyetinin farkında olmamaları, bu riske karşı çocuklarını bilgilendirme, izleme, uyarma noktasında eksik kalmalarına neden olabilmektedir.

Tablo 1. Siber zorbalık ve siber mağduriyeti etkileyen ebeveynlerle ilgili özellikler*

- Ebeveynlerin siber zorbalık hakkında bilgilerinin yetersiz olması

- Çocuklarının siber zorbalık davranışlarının farkında olmaması

- Çocuklarının siber mağdur olduğunu bilmemesi

- Çocuklarının çevrimiçi etkinliklerinin farkında olmamaları

- İhmalkar ve otoriter aile internet tutumu

- Ebeveyn ergen iletişiminin yetersiz olması

- Ebeveynlerin eğitim düzeyi

- Ebeveynden uzakta internet erişimi sağlamak (internet kafe vb)

- İnternette paylaşılan bilgiler hakkında çocuğun bilgilendirilmemesi

- Güvenli internet kullanımı hakkında çocuğunu bilgilendirmemesi

- Ebeveynlerin internet ve bilgisayar kullanma becerisinin çocuklar ve gençler tarafından yetersiz olarak alg1lanması

\footnotetext{
*Tablo ilgili literatür kullanılarak araştırmacılar tarafindan oluşturulmuştur (7,12,28-33)
} 
Çeşitli nedenlerle gerçekleşen siber zorbalık ve siber mağduriyetin çocukların ve gençlerin sağlığ üzerinde olumsuz etkileri vardır. Siber zorbalığa maruz kalan çocuk ve gençlerde en sık depresyon, anksiyete, öfke, kızgınlık, benlik saygısında azalma ve stres yaşanmaktadır (37-40). Akademik başarıda azalma, uyku problemleri, vücut ağrıları da siber mağdur olan çocuk ve gençlerde görülen problemler arasında yer almaktadır $(39,41)$. Ayrıca saldırganlık, madde kullanımı ve riskli cinsel ilişki ve intihar davranışı görülmektedir $(38,42-44)$. Çocuk ve gençlerin siber zorbalıkla başa çıkma stratejilerinin yetersiz olması (45), sıklığının artarak devam etmesi nedeniyle siber zorbalığın önlemesi ve karşılaşıldığında müdahale edilmesi için araştırmacılar tarafından çeşitli programlar geliştirilmiştir. Okul tabanlı siber zorbalık önleme programları, güvenli internet kullanımı, empati, etik, dijital vatandaşlık gibi siber dünyaya uyum eğitimleri, teknoloji tabanlı çözümler (ebeveyn filtre programları) kullanılmıştır (46-51). Literatürde siber zorbalığı önleme ve müdahale çalışmalarına ebeveynlerin de dahil edilmesinin önemi vurgulanmaktadır $(7,11,24,52,53)$. Çocuk ve gençlerin sosyal, duygusal, psikolojik, zihinsel ve fiziksel sağlı̆̆ını pek çok açıdan olumsuz etkileyen siber zorbalığın önlenmesinde ebeveynlere önemli sorumluluklar düşmektedir $(12,54)$. Ebeveynlerin siber güvenlik ve ilgili teknolojik becerilerini geliştirmelerinin yanında, çocuklarına dijital vatandaşlık becerileri ve özellikle teknolojiyi olumlu ve etik bir biçimde kullanmayı öğretmeleri önerilmektedir (53).

Ebeveynlerin dijital dünyanın getirdiği avantaj ve dezavantaj amacıyla çocuklarına rehberlik yapabilmesi için bir takım özelliklere ve yeni rollere sahip olmaları gerekmektedir (2). Bu yeni rollerden en önemlisi dijital ebeveynlik rolüdür (14).

\section{Dijital Ebeveynlik}

Birçok ebeveyn çocuklarının internette gerçekleştirdiği aktivitelerinin içeriğini sorgulamadan, kullanım süresini ve dijital cihazlara erişimini kısıtlayarak çocuklarını dijital tehditlere karşı koruduğunu düşünmekte ve kendilerini yeterli görmektedir $(55,56)$. Ancak bu yaklaşım çoğu zaman işe yaramamakta ve çocuk ve gençlerin siber zorba veya siber mağdur olmasını engelleyememektedir (56). Dolayısıyla ebeveynlerin dijital yetkinliklerini geliştirmesi gerekmektedir. $\mathrm{Bu}$ da dijital ebeveynlik stratejilerini benimseyerek gerçekleşecektir. 


\section{Dijital ebeveynlik "Dijital çağın gereksinimlerine} göre hareket eden, dijital araçlarl kullanabilen, dijital ortamlardaki olanakların farkında olan ve çocuğunu bu ortamlardaki risklere karşı koruyabilen, gerçek hayatta kişilik haklarına saygı duyulduğu gibi sanal ortamda da aynı şekilde davranılması gerektiğini çocuğuna aktaran ve teknolojik gelişmeleri takip eden ebeveynler" olarak tanımlanmıştır (14). Dijital dünya her yaştan çocuğun her türlü siber risk ve tehdide açık olduğu bir ortam olması sebebiyle dijital ebeveynlik sorumlulukları çocuğun doğumundan başlayarak yetişkinliğine kadar devam etmelidir (57). Ebeveynlerin çocuklarını çevrimiçi ortamda uygunsuz içerikten nasıl koruyacağı, siber zorbalık ile nasıl başa çıkabileceği, sosyal medya kullanımını izlemeyi ve çocuklarının eğitimi ile ilgili kararlar verirken dijital kaynakları nasıl kullanabilecekleri dijital ebeveynlik becerilerini geliştirmesi ile sağlanacaktır (58).

\section{DİJITAL EBEVEYNIN SAHIPP OLMASI} GEREKEN ROLLER VE SİBER ZORBALIĞIN ÖNLENMESİNDEKİ ÖNEMİ

Dijital ebeveynliğin genel amacı dijital dünyada çocuklarını tehditlere karşı korumak (59) ve çocuklarına rol model olarak dijital dünyada nasıl davranmalarını gerektiğini göstermektir (60). Dijital ebeveynlerin sorumluluklarını yerine getirebilmesi için sahip olması gereken roller Yurdakul ve arkadaşları (14) tarafindan (1) dijital okuryazarlık, (2) dijital dünyanın farkında olma, (3) dijital ortamda kontrol,(4) dijital etik ve yenilikçilik olarak sıralanmıştır.

1. Dijital Okuryazarlık: Siber dünyada çocukları ve gençleri en sık etkileyen tehditlerden biri olan siber zorbalığın önlenmesinde ebeveynlerin iyi bir dijital okuryazar olması önem taşımaktadır. Örneğin, internette ve ya sosyal medya hesaplarında bir bilginin doğruluğunu araştırmadan paylaşımda bulunmak (61) siber zorbalık ve siber mağduriyet ile sonuçlanabilmektedir. Dijital okuryazarlık, Ribble (62) tarafindan "Teknoloji ve teknoloji kullanımı hakkında öğretme ve öğrenme süreci” olarak tanımlanmaktadır. Dijital okuryazarlık becerisi ile bireyler internet ortamındaki bilgilerin içeriklerinin doğruluğunu saptayabilmekte, alternatif öğrenme yöntemlerini seçerek kendilerini eğitebilmektedir (63). Dijital okuryazarlık sadece internet ortamında bilgi araştırmak değil, bu bilginin günlük yaşamda 
kullanabilme yeteneği de kapsamaktadır (61). Ayrıca internet ortamında mahremiyet ve güvenlik konularına hakim olmaktır. Böylece birey hem dijital becerilerini geliştirerek güvenli internet kullanımını sağlayabilmekte hem de internetin risklerinden korunmayı bilmektedir (64). Dijital okuryazarlık seviyesi daha yüksek olan ebeveynlerin dijital okuryazarlık seviyesi düşük olanlara göre çocuklarının teknolojik gereçleri kullanma konusunda daha iyi rehberlik ettikleri bildirilmiştir (65). Ayrıca başka bir çalışmada ebeveynlerin bu becerilerinin artması çocukların siber zorbalık oranlarını azalttığı belirlenmiştir (31). Görüldüğü gibi dijital okuryazar bir ebeveyn hem teknolojik araç ve gereçleri kullanmakta sorun yaşamamalı, hem de bu araç gereçlerle aradığ bilginin doğruluğunu sorgulayabilmeli, paylaşabilmeli, dijital dünyanın tehditlerini okuyabilmelidir.

2. Dijital Etik: Siber zorbalığın önlenmesinde dijital ebeveynler dijital etik ilkeleri bilmeli ve çocuklarını bu doğrultuda yönlendirmelidir. Dijital etik internet ortamındaki "davranış standartları" olarak tanımlanmaktadır (62). Etik, bireyin karşılaştığı bir durum karşısında neyin iyi, neyin kötü, neyin doğru, neyin yanlış olduğunu bilerek davranış belirlemektir (66). Toplumda kabul gören etik davranışlar, gözlem yoluyla öğrenilerek benimsenmektedir. Örneğin bir çocuk diğer çocukların ve yetişkinlerin davranışlarını inceleyerek kendi davranışlarına şekil vermektedir. Böylece toplumun etik anlayışı gelişmektedir (67). Günümüzde internetin kullanılmasıyla dijital dünyaya aktarılan iletişimde etik kuralların olması gerekliliğini doğurmuştur. Dijital etik, internet ortamında insanların sergiledikleri davranışların açıklanmasını ve bu davranışlara ahlaki bir yaklaşım getirilmesini olarak da ifade edilmektedir (68). Daha açıklayıcı bir biçimde dijital etik, internet ortamında nasıl iletişim kurmak gerektiğini, başkalarına nasıl davranmak gerektiğini, internet ortamında görülebilen etik sorunlardan nasıl korunmak gerektiğini içermektedir (69). İnternet ortamında diğer insanlara sayg1 duymak, siber zorbalıktan kaçınmak, interneti diğer insanlar üzerinde en az olumsuz etki bırakacak şekilde kullanmak dijital etik davranışlar olarak sayılabilmektedir (62).

Bir iletişim sorunu da diyebileceğimiz siber zorbalık, internette iletişim halindeki kişilerden 
birinin karşı tarafa göstermesi gereken sosyal mesafeyi ihlal etmesi böylece sayg1 sınırının aşılmasıyla gerçekleşen bir saldırıdır (70). İnternet ortamında başkalarına ait fotoğrafları izinsiz paylaşmak, kimliğini gizleyerek bir başkası gibi davranmak, paylaşılan fotoğraflara, videolara ve ya kişisel düşüncelere karşı uygun olmayan yorumlar yapmak, iftira atmak, dedikodu çıkarmak, tehdit etmek gibi davranışlarda bulunmak ve ya maruz kalmak siber zorbalık ve siber mağduriyete neden olmaktadır. Yüz yüze iletişimde kabul görmeyecek bu davranışların internet ortamında da sergilenmemesi gerekmektedir. Çünkü internet ortamında gerçekleştirilen her davranış gelecekte eğitim ve istihdam firsatlarını etkileyebilmektedir (71). Nas1l ki günlük yaşamda ebeveynler çocuklarına evrensel etik kurallara uygun davranmaları konusunda rehberlik etme görevine sahip ise internet ortamında da çocuklarına bu konuda rehberlik etmesi gerekmektedir. Lee (72) ebeveynlerin tutumunun çocuklarında dijital etik bilincinin oluşmasında oldukça etkili olduğunu bildirmektedir. Bu nedenle ebeveynlerin dijital etik kavramının farkında olmaları gerekmektedir. Siber zorbalığın önlenmesi için dijital ebeveynlerin dijital etik ilkeleri benimseyip, çocuklarına aktarmaları son derece önemlidir.

3. Dijital Dünyanın Farkında Olma: Siber zorbalığın önlenmesinde dijital ebeveynlerin dijital okuryazar olmaları, internette etik davranışları benimsemeleri ve çocuklarına aktarmanın yanında dijital dünyanın çocukları ve kendileri için getirdiği avantaj ve dezavantajlarının farkında olması beklenmektedir (14). İnternetin iletişimi kolaylaştırması ve günlük yaşamdaki pek çok işin daha hızlı yapılmasına olanak sunması avantajları olarak sayılmaktadır. Ancak internet ile artan erişilebilirlik siber zorbalık ve siber mağduriyet riskini doğurmaktadır (73).Yapılan çalışmalarda internette günde üç saatten fazla zaman geçirmenin siber zorbalığ 1 ve siber mağduriyeti artırdığ 1 belirlenmiştir. Ad, soyad, yaş cinsiyet, fotoğraf, video, düşünce gibi birçok bilginin paylaşıldığı sosyal medya platformlarında kişisel bilgi ve iletişim bilgilerini paylaşarak kendi kendilerini ifşa etmeleri nedeniyle siber zorbalık ve siber mağduriyet gerçekleşmektedir

Çevrimiçi çok oyunculu oyunlarda da kişiliğe bürünme yoluyla yani bireyin kendisi farklı bir kişiymiş gibi tanıtması (18) nedeniyle siber 
zorbalık ve siber mağduriyet yaşanabilmektedir.

Biricik (75) tarafından yapılan çalışmanın sonucu çocukların \%80'i karşısındaki kişinin gerçek kimliğinden şüphelenmektedir. Çocuk ve gençlerin internet kullanma amacı göz önüne alındığında (76) internet kullanım süresinin artması ve vakit geçirilen ortamlarda siber zorbalık riskiyle karşı karşıya oldukları açıkça görülmektedir (77). Dijital bir ebeveynin çocuğunun kullandığı cihazlardan, internette geçirdiği sürenin, sosyal medya hesaplarının ve oyun sitelerinin içeriklerinden haberdar olması, siber zorbalık hakkında bilgi sahibi olması gerekmektedir. Böylece çocuk veya genç daha siber zorbalıkla karşılaşmadan bu risk ortadan kalkacaktır. İnternettin riskli durumlarının farkında olarak çocuklarına dijital ortamda belli kurallar getiren ebeveynlerin çocuklarının siber zorbalık riskinin azaldığı belirlenmiştir (78).

Dijital bir ebeveynin çocuğunun siber zorba veya siber mağdur olup olmadığını fark etmesi, çocuğunun davranışlarında görülen değişiklikleri izlemesi beklenmektedir (Tablo 2). Genellikle çocuklar siber zorbalık ve siber mağduriyet deneyimini ailelerinden önce arkadaşları ile paylaşmakta, yaşadıkları bu sorunu kendi kendilerine çözmeye çalışmaktadır (24). $\mathrm{Bu}$ nedenle ebeveynler çocuklarının davranışlarını önceden fark ederek siber zorbalığın önlenmesi ve müdahalesinde çocuklarına destek olabilirler (79).

4. Dijital Dünyada Kontrol: Siber zorbalığın önlenmesinde dijital ebeveynlere düşen sorumluluklardan bir diğeri de dijital ortamda kontrol sağlamaktır. Dijital dünyanın ebeveynlere getirdiği sorumluluk çocuklarının yalnızca teknolojiye erişimini sağlamak değil, etkin, yararlı ve güvenli kullanımı desteklemektir (80). Açık bir ifade ile dijital bir ebeveynden çocuğuna cihaz ve internet paketi sağlamaktan başka, çocuğunun bu imkanları nasıl kullandığını, hangi sosyal ağlarda gezdiğini, kişisel bilgilerini paylaşıp paylaşmadığını, tanımadığı kişilerle arkadaş olup olmadığını kontrol etmesi beklenmektedir $(2,14)$. Aile-çocuk iletişimi yetersiz olan ve internet aktivitelerini kontrol etmeyen ebeveynlerin çocuklarının siber mağdur olduğu belirlenmiştir (24). Tam tersi olarak internet kullanımını kontrol eden, izleyen, internetin kolaylıkları ve riskleri hakkında konuşan ebeveynlerin çocuklarının siber zorbalık riskinin azaldığı belirlenmiştir (52). Siber zorbalıkta ebeveyn kontrolü bir koruyucu faktör 
olarak değerlendirilmekte, internette ebeveyn kontrolü arttıkça çocukların siber zorbalık oranları düşmektedir (81). Ancak şu unutulmamalıdır ki ebeveynler çocuklarını dijital ortamda kontrol ederken bunu tutarlı olarak sürdürmesi gerekmektedir. Çocuğunun internet kullanımına kurallar getiren ancak bu kuralları uygulamayan ebeveynlerin çocuklarının siber zorbalık oranlarının arttığg belirlenmiştir (82). Dijital bir ebeveyn internette çocuğunun aktivitelerini kontrol ederken çocuğunun yaş düzeyine uygun şekilde yaklaşmalıdır. Erken çocukluk döneminde zamanı kısıtlama, içeriği kontrol etme gibi yaklaşımlar tavsiye edilirken bu durum ergenlik döneminde farklılaşmaktadır (83). Özellikle 15 yaş ve sonrası dönemde ebeveynler, çocukların internet kullanımları birebir kontrol etmek yerine, daha fazla yönlendirici olarak, yasal ve etik kullanımı hakkında, sosyal medya hesaplarında konum, kişisel bilgilerin paylaşmanın riskleri hakkında açıklama yapmaları beklenmektedir (80).

5. Yenilikçilik: Dijital ebeveynlerin sahip olması gereken rollerden sonuncusu yenilikçiliktir. Çok hızlı gelișen teknolojiye zaman zaman ayak uyduramayan ebeveynlerin teknik gelişmeler, güvenlik programları ve araçları hakkında ve aynı zamanda gençler arasında popüler olan içerik hakkında temel bilgiye ihtiyaçları olmaktadır (84). Dijital ebeveynlerin yeniliklere açık olması, çocuklarını ve kendilerini geliştirebilmek için teknolojinin sunduğu imkanların farkında olması gerekmektedir (14).

\section{SIBBER ZORBALIK, DİJITAL EBEVEYNLİK， VE PEDIYATRI HEMŞİRELİĞí}

Günlük yaşamda hava kirliliği, temiz suya ulaşamama, madde bağımlılığı, kazalar gibi etmenler çocuk sağlığını olumsuz etkiliyorsa dijital dünyanın taşıdığı riskler de çocuk sağlığını etkilemektedir. Güncellenen Hemşirelik Yönetmeliğinde tanımından da anlaşılacağı gibi pediyatri hemşiresinin ilk görevi " $0-18$ yaş arasındaki çocukların aile ve toplum içinde fiziksel, bilişsel, duygusal ve sosyal yönden sağllklı büyüme ve gelişmesinden" sorumlu olmaktır (85). Zaman içerisinde toplumsal değişimlerden etkilenerek yeni roller ve sorumluluklar üstlenen pediyatri hemşireleri (86) dijital dünyanın çocuk ve aile sağlığını etkilemesi nedeniyle günümüzde sahip olduğu rollere yenisi eklenmektedir. Çocukların 
internetin sunduğu avantajları kullanabilmesi, sağlığını olumsuz etkileyen davranışlardan uzak kalmasını sağlamak amacıyla anne ve babalara dijital ebeveynlik becerilerinin kazandırılması pediyatri hemşiresinin rollerindendir (13)

Pediatri hemşireleri, okul, hastane ve sağlık hizmetinin sunulduğu her alanda sağlığg geliştirme faaliyetlerinin bir parçası olarak araştırmacı, eğitici ve savunuculuk rollerini kullanarak dijital ebeveynlik stillerini başarılı bir şekilde yönetmede ebeveynlere yardımcı olabilir (59). Çeşitli nedenlerle ebeveynlerin dijital ebeveynlik farkındalıkları yetersizdir. Ebeveynin yaşının ilerlemesi, teknoloji kullanım süresinin artması ve aile içi iletişimin yetersiz olması dijital ebeveynlik rollerini yerine getirmesini olumsuz etkilemektedir. Annelerin babalara kıyasla dijital ebeveynlik farkındalığı daha fazladır (87). Dijital ebeveynliği etkileyen bu etmenlerin farkında olarak pediyatri hemşiresi, ebeveynlerin farkındalık kazanmasını sağlamak amacıyla, tüm ebeveynlere olmak üzere, yaşı ilerlemiş, zayıf aile ilişkileri olan, sorunlu teknoloji kullanımı olan ebeveynlere eğitim ve danışmanlık hizmeti sağlayabilir.
Dijital dünyanın riskleri arasında yer alan siber zorbalığı önlemek için dijital ebeveynlik becerilerinin desteklenmesi pediyatri hemşireliği uygulamaları arasındadır $\quad(7,88) . \quad$ Pediyatri hemşiresi ebeveynleri çocuklarının siber zorba ve siber mağdur olup olmadığını anlamasını sağlayacak ipuçları hakkında bilgilendirmelidir (Tablo 2). Siber zorbalığın doğru bir davranış olmadığını açıkça anlatan ebeveynlerin çocuklarının siber zorbalık davranışına katılma olasılıklarının daha düşük olduğu bildirilmektedir (11). Pediyatri hemşiresi ebeveynlere çocuğunun siber mağdur olduğunda veya siber zorbalıkta bulunduğunda nasıl davranması ve neler yapması gerektiğini anlatabilirler (89). Örneğin siber zorbalığa maruz kalan çocuğa, öfkelenmeden sakin kalarak siber zorbalık kanıtları toplaması ardından zorbalık yapan kişiye karşılık vermeden hemen engellemesi ve bu tür bir olayla karşılaştığında bir yetişkinden yardım isteyerek durumu olayın gerçekleştiği platforma şikayet etmesinin önemi anlatılmalıdır(89). Aynı zamanda ebeveyn çocuğunun siber zorbalık yaptığına şahit olduğunda, ailenin sorunu (kendi çocuğunun zorba olduğunu) kabul ederek, yargılamadan açık bir 
iletişim kurarak olayın nedenini ve nerede (sosyal medya hesabı, çevrimiçi oyun vb.) gerçekleştiğini öğrenmeli, anında zorbalık davranışını durdurması istenmeli ve mağdur olan kişinin neler hissedebileceğini anlaması için empati yapması sağlanmalıdır (90). Böylece ebeveyn çocuğu siber mağdur olduğunda izlemesi gereken adımları bilecek ve çocuğuna aktarabilecek hem de çocuğu siber zorbalıkta bulunduğunda nasıl bir yaklaşım sergilemesi gerektiğini bilerek müdahalede bulunacaktır.

\section{SONUÇ}

Çocuk ve gençlerin güvenli olmayan internet kullanımı nedeniyle yaşadıkları siber zorbalık ve siber mağduriyet, ebeveyn-çocuk arasında açık bir iletişim olmaması, ebeveynlerin sosyokültürel ve ekonomik düzeyleri, ebeveynlerin dijital dünyanın hızına ayak uyduramamaları gibi nedenlerle de gerçekleşmektedir. Günlük yaşamın tehlikelerine karşı çocuklarını koruyan ebeveynlerin dijital yaşamda gerçekleşen siber zorbalık tehlikesine karşı da çocuklarını korumak ile yükümlüdürler. Dijital ebeveynliğin amac1, dijital dünyanın avantajlarını bilerek, risklerinin farkında olarak çocuklarının internet kullanımlarını daha verimli hale getirmektedir. Hızla gelişen ve değişen teknolojinin sunduğu firsatlardan çocuklarını mahrum bırakmamak hem de etkisi ömür boyu sürebilen siber zorbalıktan kaçınma ve korunma becerisini çocuklarına kazandırmak için ebeveynlerin dijital ebeveyn olması çok önemlidir. Dijital okuryazarlık, dijital etik, dijital dünyanın farkında olma, dijital dünyada kontrol ve yenilikçiliği kapsayan dijital ebeveynlik becerisinin kazılmasında eğitim, danışmanlık, savunucu rolleri gereğince pediyatri hemşireleri yol göstericidir. Sonuç olarak, pediyatri hemşirelerinin etkin rol alarak siber zorbalığ önleme ve müdahale programlarına ebeveynlerin dahil edilmesi ve dijital ebeveynlik becerilerinin desteklenmesi önerilebilir. 
Tablo 2. Siber zorba ve siber mağdurların davranışları

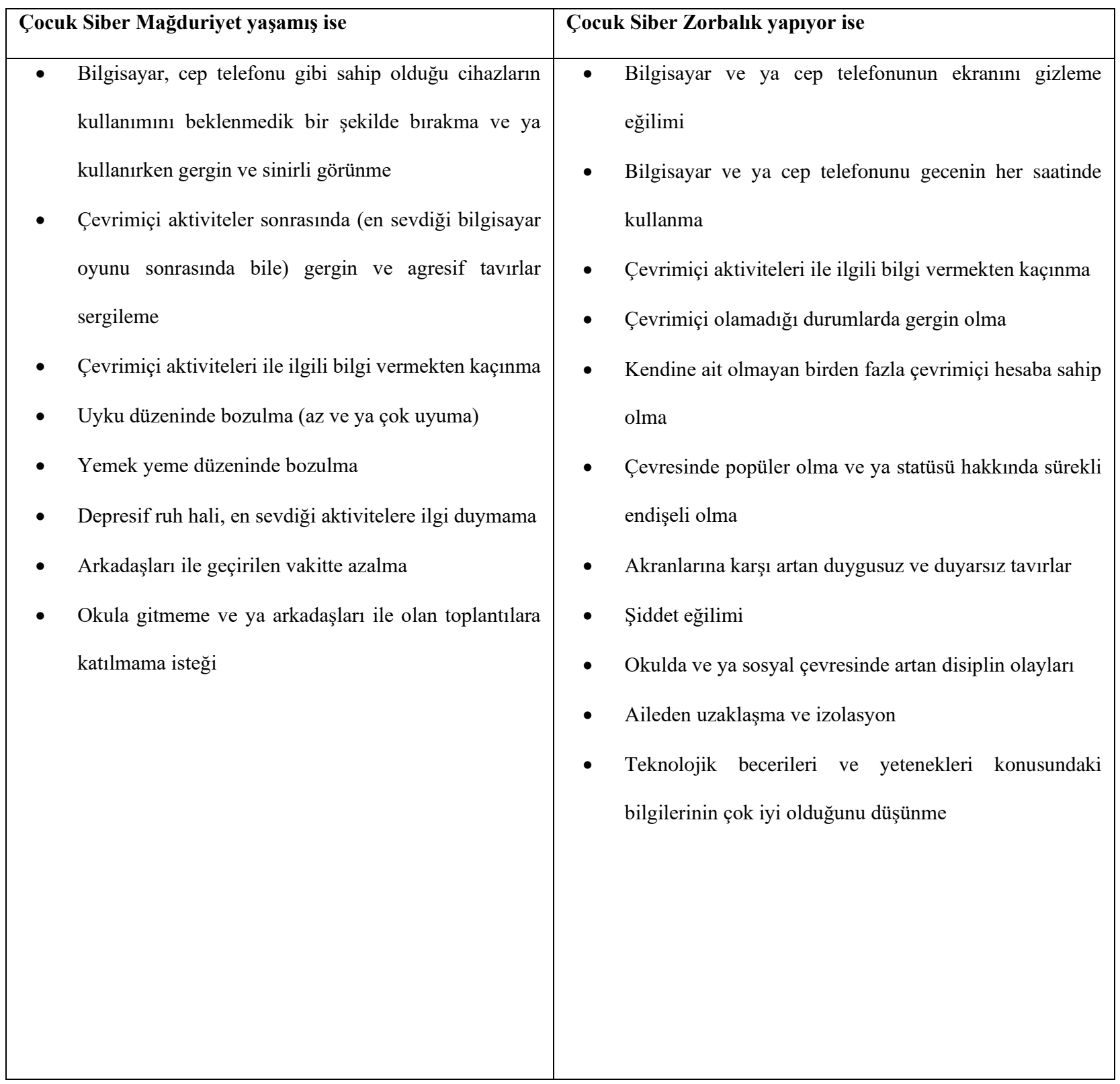

*Tablo ilgili literatür kullanılarak araştırmacılar tarafından oluşturulmuştur (79). 


\section{KAYNAKLAR}

1. Prensky M. Digital natives, digital immigrants. On the Horizon. 2001;9(5):1-5.

Erisim adresi:https://www.emerald.com/insight/content/doi/10.1108/ 10748120110424816/full/pdf?title=digital-natives-digitalimmigrants-part-1

2. Yay M. Dijital Ebeveynlik. [İnternet] İstanbul: Gülmat Matbaacılık Yayıncılık San. Tic. Ltd. Ști; 2019. s.9-10. Erișim Adresi:

https://yesilaymarket.com/Data/EditorFiles/DijitalEbeveynlik. pdf

3. OECD. Measuring the Digital Transformation: A roadmap for the future. Paris: OECD Publishing; 2019. DOI: https://doi.org/10.1787/9789264311992-en.

4. Yavuzer H, Demir İ. Yeni Kuşak Anne Babalar ve Çocukları. İstanbul: Remzi Kitabevi, 2016. s.144.

5. Ofcom. Children and Parents: Media Use and Attitudes Report 2018.UK: 2019.20 Adresi:https://www.ofcom.org.uk/_data/assets/pdf__ fi le/0024/134907/Children-and-Parents-Media-Use-and-Atti tudes-2018.pdf

6. Aral N, Doğan Keskin A. Ebeveyn bakış açısıyla 0-6 yaş döneminde teknolojik alet kullanımının incelenmesi. Addicta: The Turkish J on Add. 2018:5(2):317-348.

7. Uludasdemir D, Kucuk S.Cyber bullying experiences of adolescents and parental awareness: Turkish example. J Pediatr Nurs.2019; 44: e84-e90.

8. Uyar M, Hasdemir T. Çocukların internet'e erişimleri ve kullanım becerileri: Ankara ili örneği. Ufuk Üniversitesi Sosyal Bilimler Enstitüsü Dergisi. 2021;10 (19):7-38.

9. Kaşıkçı DN, Çağıltay K, Karakuş T, Kurşun E, Ogan C. Türkiye ve Avrupa' daki çocukların internet alışkanlıkları ve güvenli internet kullanımı. Eğitim ve Bilim. 2014; 39(171):1300-1337.

10. Nang H, Harfield A. The Nature of Technology Consumption among School Children in Lower Northern Thailand. Int. J. Interact. Mob. Technol.2019;13: 137-146.

11. Hinduja S, Patchin JW. Social Influences on cyberbullying behaviors among middle and high school students. J Youth Adolescence. 2013;42: 711-722 DOI: https://doi.org/10.1007/s10964-012-9902-4

12. Baldry AC, Sorrentino A, Farrington DP. Cyberbullying and cybervictimization versus parental supervision, monitoring and control of adolescents' online activities. Child Youth Serv Rev. 2019;96:302-307. https://doi.org/10.1016/j.childyouth.2018.11.058

13. Hutson E, Kelly S, Militello LK. Systematic review of cyberbullying interventions for youth and parents with implications for evidence-based practice. Worldviews Evid Based Nurs. 2018;15(1):72-79. DOI: 10.1111/wvn.12257.

14. Yurdakul IK, Dönmez O, Yaman F, Odabaş1, HF. Dijital ebeveynlik ve değişen roller. Gaziantep University Journal of Social Sciences. 2013:12(4):883-89.

15. Patchin J, Hinduja S. Bullies move beyond the schoolyard: A preliminary look at cyberbullying. YVJJ.2006: 4(2):148-169. DOI: https://doi.org/10.1177/1541204006286288

16. Kowalski MR, Limber PS. Electronic bullying among middle school students. Journal of Adolescent Health.2007;41:22-30. DOI: https://doi.org/10.1016/j.jadohealth.2007.08.017

17. Smith PK, Mahdavi J, Carvalho M, Fisher S, Russell S, Tippe $\mathrm{N}$. Cyberbullying: its nature and impact in secondary school pupils. JCPP. 2008:49(4) :376-385 DOI: 10.1111/j.14697610.2007.01846.x
18. Willard NE. Cyberbullying and cyberthreats: Responding to the challenge of online social aggression, threats, and distress. Champaign, IL: Research Press,2007.

19. Arıcak OT, Tanrıkulu T, Kınay H. Siber mağduriyet ölçeğinin ilk psikometrik bulguları. MJER, 2012: 11:1-6.

20. Lee C, Shin N. Prevalence of cyberbullying and predictors of cyberbullying perpetration among Korean adolescents. Comput Human Behav.2017.6: 352-358. DOI: https://doi.org/10.1016/j.chb.2016.11.047

21. Selkie EM, Fales JL, Moreno MA. Cyberbullying prevalence among US middle and high school-aged adolescents: A systematic review and quality assessment. J. Adolesc. Health. 2016,58(2):125-133. DOI: 10.1016/j.jadohealth.2015.09.026

22. Kalender MK, Keser H, Tugun V.Ortaokul ve Lise Öğrencilerinin Siber Zorbalık Görüşleri, Deneyimleri ve Müdahale Davranışları. Eğitim ve Bilim, 2019, 44(198):183196.

23. Taştekin E, Bayhan P. Ergenler arasındaki siber zorbalığın ve mağduriyetin incelenmesi. OJTAC.2018, 5(2): 21-45.

24. Zhu C, Huang S, Evans R, Zhang W. Cyberbullying among adolescents and children: a comprehensive review of the global situation, risk factors, and preventive measures. Front. Public Health. 2021,9:1-12. DOI: https://doi.org/10.3389/fpubh.2021.634909

25. Wegge D, Vandebosch $H$, Eggermont $S$. Who bullies whom online: A social network analysis of cyberbullying in a school context. Communications, 2014; 39(4). DOI:10.1515/commun-2014-0019.

26. O'dea, B., Campbell, A. (2012). Online Social Networking and the Experience of Cyber-Bullying, Ebook Series: Annual Review of Cybertherapy and Telemedicine, 181:212-217. DOI:10.3233/978-1-61499-121-2-212.

27. Martín-Criado JM, Casas JA, Ortega-Ruiz R. Parental supervision: predictive variables of positive involvement in cyberbullying prevention. Int $\mathrm{J}$ Environ Res Public Health.2021,18(4):1562. DOI: 10.3390/ijerph18041562.

28. Barlett PC, Fennel M. Examining the relation between parental ignorance and youths' cyberbullying perpetration. Psychol Pop $\begin{array}{llll}\text { Media Cult. 2018:7(4):547 } \quad \text { 560.DOI: } & \end{array}$ https://doi.org/10.1037/ppm0000139

29. Çimen İD. Ergenlerde siber zorbalık, internet aile tutumu ve aile işlevselliğinin etkisi. Anadolu Psikiyatri Dergisi. 2018:19(4):397-404. DOI: 10.5455/apd.282841.

30. Zurcher JD, Holmgren HG, Coyne SM, Barlett CP, Yang C. Parenting and cyberbullying across adolescence. Cyberpsychol Behav Soc Netw.2018;21(5):294-303. DOI: https://doi.org/10.1089/cyber.2017.0586

31. Akbaba S, Eroğlu Y. İlköğretim öğrencilerinde siber zorbalık ve mağduriyetin yordayıcıları. Uludağ Üniversitesi Eğitim Fakültesi Dergisi. 2013;26(1):105-122.

32. Mehari KR, Moore W, Waasdorp TE, Varney O, Berg K, Leff SS. Cyberbullying prevention: Insight and recommendations from youths, parents, and paediatricians. Child: Care Health Dev. 2018;44(4), 616-622. DOI: 10.1111/cch.12569.

33. Eroğlu Y, Aktepe E, Akbaba S, Isik A, Özkorumak E. The investigation of prevalence and risk factors associated with cyber bullying and victimization. Egitim ve Bilim, 2015;40(177):93-107.

34. İnan-Kaya G, Mutlu-Bayraktar D, Y1lmaz Ö. Digital parenting: Perceptions on digital risks. Kalem Uluslararası Eğitim ve İnsan Bilimleri Dergisi.2018; 8(1), 131-157.

35. Caivano O, Leduc K, Talwar V. When you think you know: The effectiveness of restrictive mediation on parental awareness of cyberbullying experiences among children and 
adolescents. Cyberpsychology (Brno). 2020;14(1):1-15. DOI: https://doi.org/10.5817/CP2020-1-2

36. Alfakeh SA, Alghamdi AA, Kouzaba KA, Altaifi MI, AbuAlamah SD, Salamah MM. Parents' perception of cyberbullying of their children in Saudi Arabia. J Fam Community Med [serial online] 2021 [cited 2021 Aug 30];28:117-24. Available from: https://www.jfcmonline.com/text.asp?2021/28/2/117/315730

37. Calpbinici P, Tas Arslan F. Virtual behaviors affecting adolescent mental health: The usage of Internet and mobile phone and cyberbullying. J Child Adolesc Psychiatr Nurs. 2019;32(3):139-148. DOI: https://doi.org/10.1111/jcap.12244

38. Fisher BW, Gardella JH, Teurbe-Tolon AR. Peer cybervictimization among adolescents and the associated internalizing and externalizing problems: A meta-analysis. J Youth Adolesc. 2016: 45(9), 1727-1743. DOI: 10.1007/s10964-016-0541-z.

39. Kowalski RM, Limber SP. Psychological, physical, and academic correlates of cyberbullying and traditional bullying. J Adolesc Health. 2013;53:13-20. https://doi.org/10.1016/j.jadohealth.2012.09.018

40. Aoyama I, Saxon TF, Fearon DD. Internalizing problems among cyberbullying victims and moderator effects of friendship quality. Multicultural Education \& Technology Journal. 2011;5(2):92-105.

41. Erreygers S, Vandebosch H, Vranjes I, Baillien E, De Witte H. The longitudinal association between poor sleep quality and cyberbullying, mediated by anger. Health Commun. 2019;34(5): 560-566. DOI: 10.1080/10410236.2017.1422098.

42. Kim S, Colwell SR, Kata A, Boyle MH, Georgiades K. Cyberbullying victimization and adolescent mental health: Evidence of differential effects by sex and mental health problem type. J Youth Adolesc.2018 Mar 1;47(3):661-72. DOI: 10.1007/s10964-017-0678-4.

43. Akbıyık C, Kestel M. Siber zorbalığın öğrencilerin akademik, sosyal ve duygusal durumları üzerindeki etkisinin incelenmesi. Mersin Üniversitesi Eğitim Fakültesi Dergisi.2016;12(3):844859. DOI: https://doi.org/10.17860/mersinefd.282384

44. Bauman S, Toomey RB, Walker JL. Associations among bullying, cyberbullying, and suicide in high school students. J. Adolesce. 10.1016/j.adolescence.2012.12.001

45. Hamm MP, Newton AS, Chisholm A, Shulhan J, Milne A, Sundar P, Ennis H, Scott SD Hartling L. Prevalence and effect of cyberbullying on children and young people: A scoping review of social media studies. JAMA Pediatr. 2015 Aug;169(8):770-7. DOI: 10.1001/jamapediatrics.2015.0944.

46. Ortega-Ruiz R, Del Rey R, Casas JA. Knowing, building, and living together on Internet and social networks: The ConRed cyber bullying prevention program. Int J Conf Violence.2012; 6(2): 303-313. DOI: https://doi.org/10.4119/ijcv-2921

47. Williford A, Elledge LC, Boulton AJ, DePaolis KJ, Little TD, Salmivalli C. Effects of the KiVa Antibullying Program on cyberbullying and cybervictimization frequency among Finnish youth. J Clin Child Adolesc Psychol. 2013;42(6):82033. DOI: $10.1080 / 15374416.2013 .787623$.

48. W"olfer R, Schultze-Krumbholz A, Zagorscak P, J"akel A, G*obel K, Scheithauer H. Prevention 2.0: Targeting cyberbullying @ school. Prev Sci.2014 Dec;15(6):879-87.doi: 10.1007/s11121-013-0438-y.

49. Garaigordobil M, Mart'inez-Valderrey V. Impact of Cyberprogram 2.0 on different types of school violence and aggressiveness. Front Psychol. 2016; 7: 428. DOI: 10.3389/fpsyg.2016.00428

50. Palladino BE, Nocentini A, Menesini E. Evidence-based intervention against bullying and cyberbullying: Evaluation of the NoTrap! program in two independent trials. Aggress Behav.2016;42(2):194-206. DOI: 10.1002/ab.21636.

51. Ortega-Barón J, Buelga S, Ayllón E, Martínez-Ferrer B,Cava MJ. Effects of intervention program Prev@ cib on traditional bullying and cyberbullying. Int. J. Environ. Res. Public Health. 2019;16(4):527 DOI: https://doi.org/10.3390/ijerph16040527

52. Roberto AJ, Eden J, Deiss DM, Savage MW, Ramos-Salazar L.The short-term effects of a cyberbullying prevention intervention for parents of middle school students. Int J Environ Res Public Health. 2017 Sep; 14(9): 1038. DOI: 10.3390/ijerph14091038

53. Kaluarachchi C, Warren M, Jiang, F. Responsible use of technology to combat Cyberbullying among adolescents. Australasian Journal of Information Systems, 2020;24. DOI: https://doi.org/10.3127/ajis.v24i0.2791

54. Gómez-Ortiz O, Apolinario C, Romera EM, Ortega-Ruiz R. The role of family in bullying and cyberbullying involvement: Examining a new typology of parental education management based on adolescents' view of their parents. Soc. Sci. 2019;8(1): 25. DOI: https://doi.org/10.3390/socsci8010025.

55. Özsoy D, Atılgan SS. Kuzeydoğu Anadolu Bölgesi'ndeki 0-8 yaş grubu çocukların internet kullanımı ve bu kapsamda ebeveyn arabuluculuğu: Nitel bir araştırma. Selçuk İletişim. 2018;11(2), 96-125. DOI: https://doi.org/10.18094/josc.415323

56. Elsaesser C, Russell B, Ohannessian CM, Patton D. Parenting in a digital age: A review of parents' role in preventing adolescent cyberbullying. Aggress. Violent Behav. 2017;35: 62-72. DOI: https://doi.org/10.1016/j.avb.2017.06.004

57. Tosun N, Mihci C. An Examination of Digital Parenting Behavior in Parents with Preschool Children in the Context of Lifelong Learning. Sustainability, 2020;12(18):7654. DOI: $10.3390 /$ su 12187654

58. Huang G, Li X, Chen W, Straubhaar JD. Fall-behind parents? The influential factors on digital parenting self-efficacy in disadvantaged communities. Am Behav Sci. 2018;62(9), 11861206. DOI: https://doi.org/10.1177/0002764218773820

59. Kavitha K, Sikandar BJ. Digital Parenting: Issues, Challenges and Nursing Implications. Journal of Pediatric Surgical Nursing. 2021;12(3): DOI:10.1097/JPS.0000000000000303

60. Zeybekoğlu Akbaş Ö, Dursun C. Teknolojinin aileye etkisi: değişen ailenin dijital ebeveyn ve çocukları. Turkish Studies Social.2020;15(4):2245-2265. https://dx.doi.org/10.29228/TurkishStudies.43395

61. Karabacak Zİ, Sezgin AA. Türkiye'de dijital dönüşüm ve dijital okuryazarlik. Türk İdare Dergisi, 2019; 1(488):319-343. Erișim Adresi: https://app.trdizin.gov.tr/publication/paper/detail/TXpNMU16 STRPQT09

62. Ribble M. Digital citizenship in schools: Nine elements all students should know. International Society for Technology in Education. (3rd ed.). Washington DC: International Society for Technology in Education;2015.

63. Karaboğa MT. Dijital medya okuryazarlığında anne ve baba eğitimi. OPUS Uluslararası Toplum Araştırmaları Dergisi. 2019;14(20), 2040-2073. DOI: 10.26466/opus.601942

64. Nicholas H, Ng W. Mobile Digital Literacy of Australian Adolescent Students. IJDLDC.2019; 10(3):32-48. DOI: 10.4018/IJDLDC.2019070103

65. Nikken P, Opree SJ. Guiding young children's digital media use: SES-differences in mediation concerns and competence. J Child Fam Stud.2018;27(6):1844-1857. DOI: 10.1007/s10826018-1018-3.

66. Burkhardt MA, Nathaniel AK. Çağdaş Hemşirelikte Etik. Çeviri Editörleri: Alpar ŞE, Bahçecik N, Karabacak Ü. (3.bask1), Istanbul: Istanbul Tip Kitapevi; 2013. 
67. Preece J. Etiquette online: From nice to necessary. Communications of the ACM, 2004;47(4):56-61. DOI: https://doi.org/10.1145/975817.975845

68. Önce Ş. Etiğin dijital etiğe dönüşümü üzerine. ISOPHOS.2019;2(3):59-85.

69. Sari D, Rejekiningsih T, Muchtarom M. Students' Digital Ethics Profile in the Era of Disruption: An Overview from the Internet Use at Risk in Surakarta City, Indonesia. iJIM. 2020;14(3):82-93.

70. Dilmaç JA. Dijital ortamda sapkınlık: siber zorbalık, Turkish Studies Social Sciences 2020;15(3):1087- 1099. DOI: https://dx.doi.org/10.29228/TurkishStudies.39895

71. Hollandsworth R, Donovan J, Welch M. Digital citizenship: You can't go home again. TechTrends. 2017; 61(6): 524-530. DOI: https://doi.org/10.1007/s11528-017-0190-4

72. Lee YJ. The effect of self-control and parenting attitude on cyberbullying: focus on mediating cyber ethics. Medico Legal Update. 2019;19(2):596-602.

73. Abdul Rahman NA, Hussein N, Rusdi SD, Abd Aziz ZDAA. Factors influencing cyberbullying behavior among Malaysian tertiary students. Advance in Business Research International Journal, 2020;6(2): 44-53.

74. Casas JA, del Rey R, Ortega-Ruiz R. Bullying and cyberbullying: Convergent and divergent predictor variables. Comput. Hum. Behav. 2013;29(3):580-587. DOI: https://doi.org/10.1016/j.chb.2012.11.015

75. Biricik Z. Çcukların oynadığ dijital oyunlara ilişkin dijital ebeveynlerinin farkındalıkları üzerine bir inceleme. Erciyes İletişim Dergisi. 2021;8(2):575-597. DOI: https://doi.org/10.17680/erciyesiletisim.785287

76. Avşar F, Ayaz-Alkaya S. Erken adölesan dönemde çocukların internet kullanım alışkanlıkları ve psikososyal sağlık durumlarının incelenmesi. Turkiye Klinikleri J Nurs Sci. 2021;13(2):258-65 DOI: 10.5336/nurses.2020-78416

77. Taylan H. H., Aydın F., Topal M. Ortaokul Öğrencilerinin Sanal Zorba Olma Durumlarının Çeşitli Değişkenler Açısından İncelenmesi: Sakarya İli Örneği. Online Journal of Technology Addiction and Cyberbullying. 2017; 4(1): 41-59.

78. Mesch GS. Parental mediation, online activities, and cyberbullying. Cyberpsychol Behav.2009 Aug;12(4):387-93. DOI: $10.1089 / \mathrm{cpb} .2009 .0068$.

79. Hinduja S, Patchin JW. Bullying Beyond the Schoolyard: Preventing and Responding to Cyberbullying (2nd Ed.). Thousand Oaks, CA: Sage Publications, 2015. (9781483349930).

80. İşman A, Odabaşı HF, Akkoyunlu B. Eğitim Teknolojileri Okumaları 2016. İçinde: Dijital Dünyanın Ailesi: İnternetik Aile, Yaman F, Dönmez O, Yurdakul IK, Odabaşı HF. (11. Bölüm ss. 173-192). Ankara: Salmat Basım Yayıncılık Ambalaj Sanayi Tic. Ltd. Şti.;2016.

81. Padır MA, Ayas T, Horzum MB. Examining the relationship among Internet parental style, personality, and cyberbullying/victimization. JTES.2021;5(1):56-69. DOI: https://doi.org/10.46328/ijtes. 160

82. Katz I, Lemish D, Cohen R, Arden A. When parents are inconsistent: Parenting style and adolescents' involvement in cyberbullying. Journal of Adolescence, 2019;74:1-12. DOI: https://doi.org/10.1016/j.adolescence.2019.04.006

83. Coyne SM, Radesky J, Collier KM, Gentile DA, Linder JR, Nathanson AI, Ramussen SMR, Rogers J. Parenting and digital media. Pediatrics, 2017; 140(Supplement 2), S112-S116. DOI: https://doi.org/10.1542/peds.2016-1758N

84. Livingstone S, Byrne J. Parenting in the digital age: The challenges of parental responsibility in comparative perspective. In: Digital Parenting: The Challenges for Families in the Digital Age, Yearbook 2018 / [ed] Mascheroni, Giovanna, Cristina Ponte, \& Ana Jorge, Gothenburg:
Nordicom, University of Gothenburg; 2018:p. 19-30. Avaliable from: http://norden.divaportal.org/smash/get/diva2:1535895/FULLTEXT01.pdf

85. Hemşirelik Yönetmeliğinde Değişiklik Yapılmasına Dair Yönetmelik; 2011. Erişim Adresi: https://www.resmigazete.gov.tr/eskiler/2011/04/201104195.htm

86. Şenol S. Tarih boyunca pediatri hemşiresinin rol ve işlevleri. Türkiye Klinikleri J Pediatr Nurs-Special Topics. 2018;4(1):17

87. Manap A, Durmuş E.Dijital Ebeveynlik Farkındalığının Aile içi Roller ve Çocukta İnternet Bağımlılığına Göre İncelenmesi. Uluslararası Eğitim Araştırmaları Dergisi. 2021;12(1):141-156.

88. Hinduja S, Patchin JW. Cyberbullying: Top Ten Tips for Teens. Cyberbullying Research Center;2020. Retrieved (28.06.2021), from https://cyberbullying.org/Cyberbullying-Top-Ten-TipsHealth-Care-Providers.pdf.

89. Hinduja S, Patchin JW. Responding to Cyberbullying: Top ten tips for teens. Cyberbullying Research Center;2018. Retrieved [28.06.2021], from https://cyberbullying.org/Top-Ten-TipsTeens-Response.pdf

90. Hinduja S, Patchin JW. What To Do When Your Child Cyberbullies Others: Top Tips for Parents. Cyberbullying Research Center; 2018 Retrieved (28.06.2021), from https://cyberbullying.org/tips-for-parents-when-your-childcyberbullies-others.pdf 